\title{
Characteristics and Cause Analysis of Local Rainstorms When Subtropical High Moving North
}

\author{
Yuhong Wang \\ Hebei Meteorological Observatory \\ Shijiazhuang, China \\ rainbowsuin@126.com
}

\author{
Jiangbo Li \\ Hebei Meteorological Observatory \\ Shijiazhuang, China \\ 506265276@qq.com
}

\author{
Yuhui Duan \\ Hebei Meteorological Observatory \\ Shijiazhuang, China \\ 157675946@qq.com
}

\section{一次发生在副高北抬过程中的局地暴雨特征与触 发机制分析}

\author{
王玉虹 \\ 河北省气象台 \\ 石家庄 050021, 河北, 中国 \\ rainbowsuin@126.com
}

\author{
李江波 \\ 河北省气象台 \\ 石家庄 050021, 河北, 中国 \\ 506265276@qq.com
}

\author{
段宇辉 \\ 河北省气象台 \\ 石家庄 050021，河北，中国 \\ 157675946@qq.com
}

\begin{abstract}
Using conventional meteorological observation data, automatic weather station data, radar data and Final Operational Global Analysis (FNL) data, and focusing on the local rainstorms of Hebei province in the process of subtropical high moving north on 20-22 July 2017, the meso-scale characteristics and reasons are analyzed in this paper. Firstly, the local rainstorms belong to the heavy rain caused by summer monsoon moving north, and the distribution of rainfall is extremely uneven, with 3 strong rainfall centers located in Qinhuangdao, Shijiazhuang, and Langfang. Secondly, the difference of heat and water vapor causes the different characteristics of 3 centers: local rainstorm in Qinhuangdao are accompanied by large-scale energy front and water vapor transportation, and radar echoes are banded and mixed; while local rainstorms in Shijiazhuang and Langfang occur at high temperature and moisture environment without large-scale water vapor transportation, and the radar echoes are dense block convective echoes. Lastly, the trigger mechanisms of the 3 strong rainfall centers are different: the local rainstorm in Qinhuangdao is triggered by the shear lines in middle and low level, and multiple convective cells affect successively resulting in "train effect"; while the local rainstorms generated by meso-scale convective systems in Shijiazhuang and Langfang are triggered by the northeast or east wind in the boundary layer.
\end{abstract}

Keywords-subtropical high moving north, local rainstorm, radar characteristics, trigger mechanism

摘要一利用常规气象观测资料、自动站资料、雷达和 FNL 再分析资料, 对 2017 年 7 月 20-22 日副高持续北抬过程中的 河北省局地暴雨中尺度特征进行了深入分析, 并就其成因进 行了探讨。首先, 本次局地暴雨属于夏季风北上产生的暴 雨, 雨量分布极为不均, 有 3 个强降水中心, 分别位于秦皇 岛、石家庄、廊坊。其次, 环境热力和水汽的差异导致 3 个 强降水中心的特征不同: 秦皇岛的局地暴雨伴随有天气尺度 的能量锋和水汽输送, 雷达回波呈带状混合性回波; 石家庄 和廊坊的局地暴雨发生在高温高湿的环境中, 没有天气尺度 的水汽输送, 雷达回波为结构密实的块状对流回波。最后, 3 个强降水中心的触发机制不同: 秦皇岛局地暴雨由中低层切 变线触发, 多个对流单体相继影响, 造成列车效应; 石家庄
和廊坊的局地暴雨由边界层东北风或偏东风渗透触发中尺度 对流系统并产生暴雨。

\section{关键词一副高北抬, 局地暴雨, 雷达特征, 触发机制}

\section{I. 引言}

西太平洋副热带高压（以下简称 “副高”) 是影响 我国东部地区夏季降水的重要天气系统之一, 它的西伸 和北抬与我国雨带的由南往北移动密切相关 ${ }^{[1]}$ 。副高边 缘暴雨是华北盛夏期暴雨中非常重要的一类, 经常给国 家财产和人民生活带来重大损失, 因此受到华北地区气 象学者的广泛研究 ${ }^{[2-4]}$ 。根据以往研究和统计, 多数暴雨 发生在副高南撤东退的过程中 ${ }^{[5]}$, 也有少数发生在副高 北抬西进的过程中 ${ }^{[6]}$ 。2017 年 7 月 20-22 日的局地暴雨 发生时, 大尺度环流形势呈纬向, 副高属于持续北抬西 进类, 局地暴雨发生在副高边缘, 落区和强度具有明显 的不均匀性。整个过程持续约 20 个小时, 先后出现 3 个 暴雨中心, 而暴雨以外的地区降水量级以小雨为主, 可 见此次降水过程时空分布高度不均匀, 并非由单一尺度 天气系统造成。

表 1 给出了 3 个暴雨区发生的时间、地点以及暴 雨、大暴雨站数。2 1 日凌晨秦皇岛地区出现暴雨站数高 达 91 个, 而大暴雨站数为 8 个; 21 日上午和夜间石家 庄和廊坊地区出现暴雨站数分别为 59 个和 20 个, 大暴 雨站数均达到 9 个, 说明这两个地区的强降水雨量分布 更为不均, 降水极端性更强。

表 1. 三个暴雨区发生的时间、地点和暴雨、大暴雨站数

\begin{tabular}{|c|c|c|c|}
\hline 时间 & 地点 & 暴雨站数 & $\begin{array}{c}\text { 大暴雨 } \\
\text { 站数 }\end{array}$ \\
\hline 21 日 $02-08$ 时 & 秦皇岛 & 91 & 8 \\
\hline 21 日 $08-14$ 时 & 石家庄 & 59 & 9 \\
\hline $\begin{array}{c}21 \text { 日 } 20 \text { 时- } \\
22 \text { 日 } 02 \text { 时 }\end{array}$ & 廊坊 & 20 & 9 \\
\hline
\end{tabular}


本文首先介绍此次局地暴雨发生时的天气形势和环 境场特征, 然后重点分析 3 个暴雨区的中尺度特征和触 发机制, 以期能够加强对副高北抬降水特点的理解, 为 以后副高边缘局地暴雨的预报预警工作提供预报着眼 点。

\section{II. 天气形势和环境场特征分析}

7 月 20 日到 21 日，500 百帕上副高呈东西带状持续 北抬, 588 线边缘伴随高空急流的南侧边界, 环流形势 呈纬向型。低层 850 百帕有一东北西南向切变线东移南 压, 南侧伴随西南急流输送水汽, 河北省中南部地区比 湿达到 $18 \mathrm{~g} / \mathrm{kg}$ 。地面气压场呈北高南低的型式, 锋面两 侧湿度差异很大, 锋前暖区有倒槽辐合, 河北省中南部 地区高温高湿能量积聚 (温度 $\geq 35{ }^{\circ} \mathrm{C}$, 露点温度 $\geq 26{ }^{\circ} \mathrm{C}$ )。此外, 降水开始前乐亭 20 日 20 时和邢台 21 日 08 时的探空观测统一显示出不稳定能量大、能量抑制 适中、抬升高度低、沙氏指数小、层结上干下湿的特 点, 上述指标表明将出现短时强降水的可能性很大。

环境场特征 (能量条件、水汽条件和动力条件) 分 析发现 3 个明显特征。

第一, 河北省中南部地区 850 百帕假相当位温普遍 达到 $82^{\circ} \mathrm{C}$ 以上, 说明暖湿气团非常强盛、中南部地区 的温湿和能量条件非常有利于短时强降水等对流性天气 发生，假相当位温密集带即能量锋区或湿斜压锋区自北 向南逐渐南压至秦皇岛-唐山-天津一带, 系统湿斜压性 特别强。在关于夏季风北界指标的多项研究中 [7-9], 850 百帕假相当位温的取值常被作为夏季风到达的标志, 虽 然不同作者的阈值略有不同，但基本均在 56-66 ${ }^{\circ} \mathrm{C}$ 之 间。此外，降水前一天 20 日 14 时地面露点温度达到
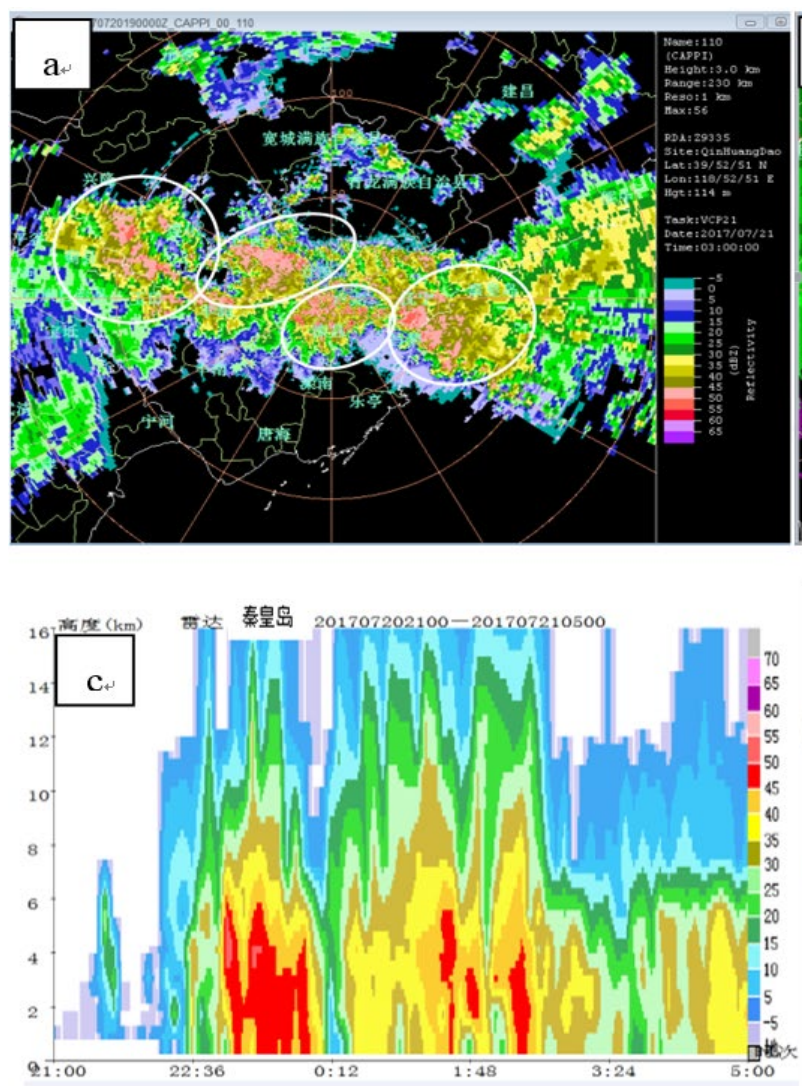

图 1. 秦皇岛雷达站 21 日 03 时 00 分 $1.5^{\circ}$ 仰角的基本反射率（a）、平均径向速度（b）；20日 21 时-21日 05 时户远寨附近反射率剖面图

(c) 及对应小时降水量 (d)
26-29 ${ }^{\circ} \mathrm{C}$, 具有明显的热带海洋气团性质, 因此此次降 水过程属于夏季风随副高北上产生的暴雨, 降水效率会 非常高。

第二, 除西北部地区以外, 河北省大部分地区整层 大气可降水量可达 $56 \mathrm{~mm}$ 以上, 部分地区高达 $60 \mathrm{~mm}$ 以上, 局地水汽十分充沛。相应地, 850 百帕比湿达到 $16 \mathrm{~g} / \mathrm{kg}$ 及以上, 绝对湿度大。但是从风场配置来看, 湿 平流较弱, 仅在秦皇岛、唐山一带略明显。从 3 个暴雨 中心发生时段的 850 百帕水汽通量散度的分布可以看 出, 21 日凌晨秦皇岛地区水汽通量散度为负, 有明显的 水汽通量辐合, 说明秦皇岛地区的降水有外来水汽的输 送；21日上午石家庄地区水汽通量散度大约为 0 , 没有 明显的水汽通量辐合, 21 日夜间廊坊地区水汽通量散度 为正, 有明显的水汽通量辐散, 说明石家庄、廊坊的降 水水汽主要来自于本地, 外来水汽输送不显著。

第三，动力条件方面，3 个暴雨中心发生时段的 700 百帕相对浴度平流的分布情况显示 21 日凌晨秦皇岛地区 为正相对浴度平流区, 伴随系统性上升运动, 说明秦皇 岛地区的降水有天气尺度辐合上升运动相对应; 21 日上 午和夜间石家庄和廊坊地区为负相对浴度平流或相对浴 度平流为 0 , 说明石家庄、廊坊的降水没有天气尺度辐 合上升运动相对应, 其上升运动来自于中小尺度系统的 触发和维持。

\section{III. 各暴雨中心的中尺度特征}

图 1 给出了秦皇岛 21 日 03 时 00 分 $1.5^{\circ}$ 仰角的基 本反射率、平均径向速度、强降水区的反射率剖面图以 及相应的小时降雨量。从图中可以看出, 积状云回波呈 东西带状分布，有多个单体相继影响唐山、秦皇岛一
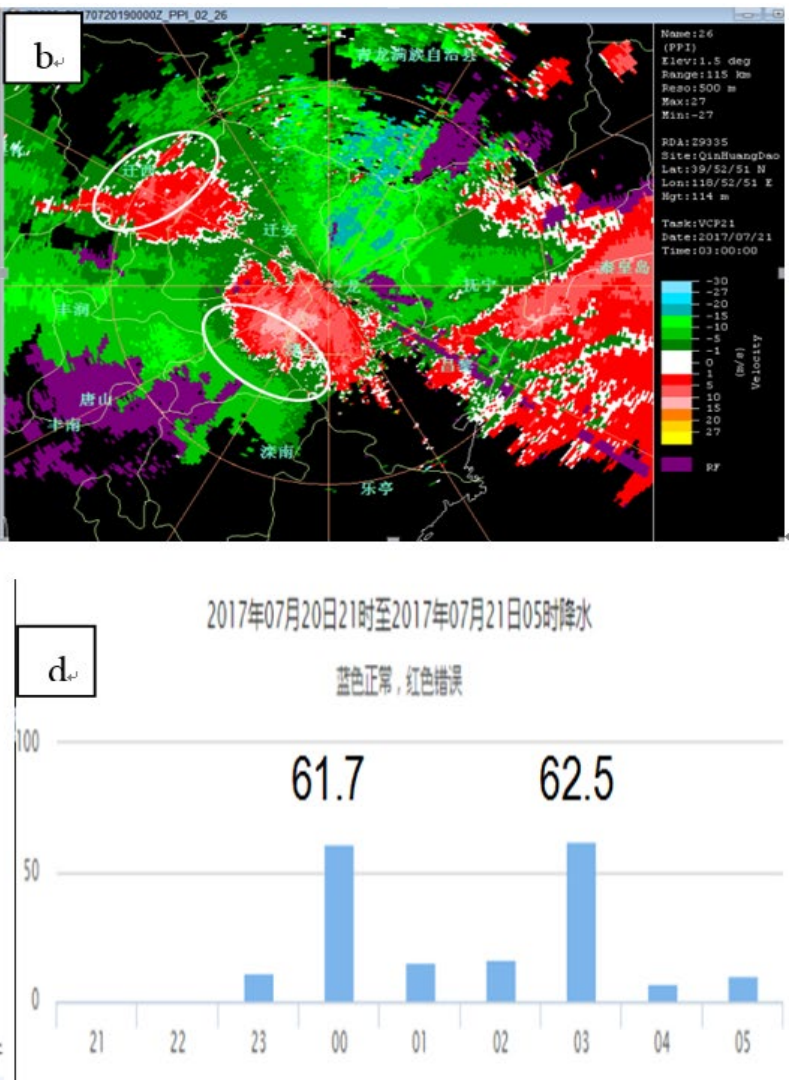
带、形成列车效应, 速度图上存在逆风区, 有风向辐 合; 从剖面图上可以看出对流单体质心低、强度大，属 于降水效率高的海洋型对流, 户远寨附近在 20 日 23 时21 日 00 时、 21 日 02 时左右相继有强回波影响, 强回波 高度 $6 \mathrm{~km}$ 以下，反射率因子达到 $45 \mathrm{dBZ}$ 以上，对应 21 日 00 时和 03 时的小时降雨量分别高达 $61.7 \mathrm{~mm}$ 和 62.5 $\mathrm{mm}$ 。

从石家庄 21 日 10 时 54 分 $1.5^{\circ}$ 仰角的基本反射 率、平均径向速度、强降水区的反射率剖面图以及相应 的小时降雨量（图 2) 可以看出，积状云回波呈块状向 东南方向移动, 回波前沿出流明显, 雷暴前方不断有新 生单体生成, 速度图上风随高度顺转有暖平流, 低层存 在东北风急流; 剖面图上可以看到对流单体质心低、降 水效率高, 葍城附近 11-13 时有反射率因子大于 $45 \mathrm{dBZ}$ 的强回波影响, 强降水主要集中在 12 时、 13 时, 小时 降水量分别达到 $82.8 \mathrm{~mm} 、 57.9 \mathrm{~mm}$ 。

由于廊坊本站没有雷达，从附近的北京站 21 日 22 时 00 分的 $1.5^{\circ}$ 仰角的基本反射率、平均径向速度、强降 水区的反射率剖面图以及相应的小时降雨量（图 3) 可 以看出, 该阶段的雷达回波结构密实、尺度较小、移速 缓慢, 速度图上各个仰角均为偏东风; 剖面图上可以看 到廊坊安次附近 19-23 时有强回波影响, 单体强度超过 $45 \mathrm{dBZ}$ ，持续时间 $3 \mathrm{~h}$ 以上，使得该时段内逐小时降水 量维持在 30-50 $\mathrm{mm}$ 的较高水平上。

综合以上分析, 3 个暴雨中心的雷达回波均有结构 密实、反射率因子梯度大、强度中心大于 $45 \mathrm{dBZ}$ 、对流 单体质心低、回波高度低、降水效率高的特点, 且强单
体影响时间与短时强降水时段有很好的对应关系。但回 波的形状、移速、生命史和径向速度场特征却有明显的 差异, 这主要是因为每个地区的暴雨是由不同尺度天气 系统触发而形成的, 下面将对其触发机制进行分析。

\section{IV. 各暴雨中心的触发机制}

结合天气形势和环境场特征来看, 秦皇岛地区的暴 雨是在 850 百帕切变线和地面冷锋东移影响时产生, 并 伴随天气尺度的上升运动和水汽通量辐合, 是由天气尺 度动力系统触发形成, 因此雷达回波呈带状分布。从预 报的角度, 该地区的暴雨预报把握性也比较大, 这里重 点分析从天气尺度系统上不好发现的石家庄和廊坊地区 暴雨的形成机制。

石家庄暴雨发生时, 石家庄地区已位于 850 百帕切 变线的后部, 从高空环流看, 影响系统不明显。21日 09 时自动站资料显示地面锋区南压, 冷空气从东北路径渗 透, 地面倒槽位于平原地区中部, 石家庄以东和以西温 差较大, 且有东北风风速辐合、东北风和东南风两路水 汽汇集, 容易触发对流产生。从 21 日石家庄站风廓线雷 达的垂直风场随时间的变化 (图 4) 可以看出, 强降水 开始 (北京时 10 时) 前 $1500 \mathrm{~m}$ 高空有偏东气流起到冷 垫作用, 强降水开始后 $1000 \mathrm{~m}$ 以下出现东北风急流; 风场反演的温度平流显示 09 时之前, $1200 \mathrm{~m}$ 内的边界 层有暖平流的输送, 同时在 $2000 \mathrm{~m}$ 有冷平流, 造成层 结不稳定, 对流触发以后随着系统发展, 冷平流中心的 质心开始下降, 伴随有强降水, 11 时冷平流质心在近地
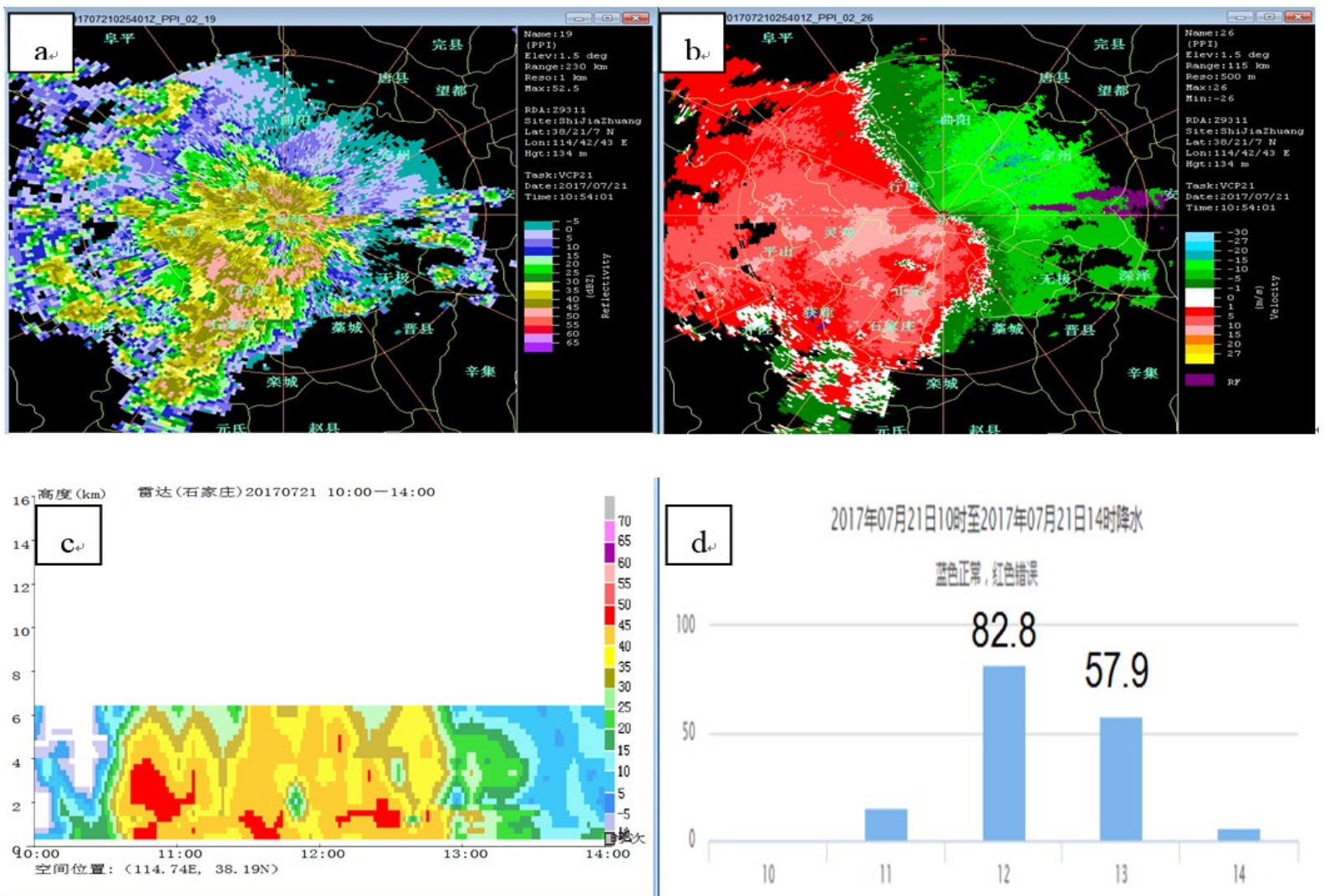

图 2. 石家庄雷达站 21 日 10 时 54 分 $1.5^{\circ}$ 仰角的基本反射率（a）、平均径向速度（b）；21日 10 时-14 时蓄城附近反射率剖面图（c）及对 应小时降水量（d） 

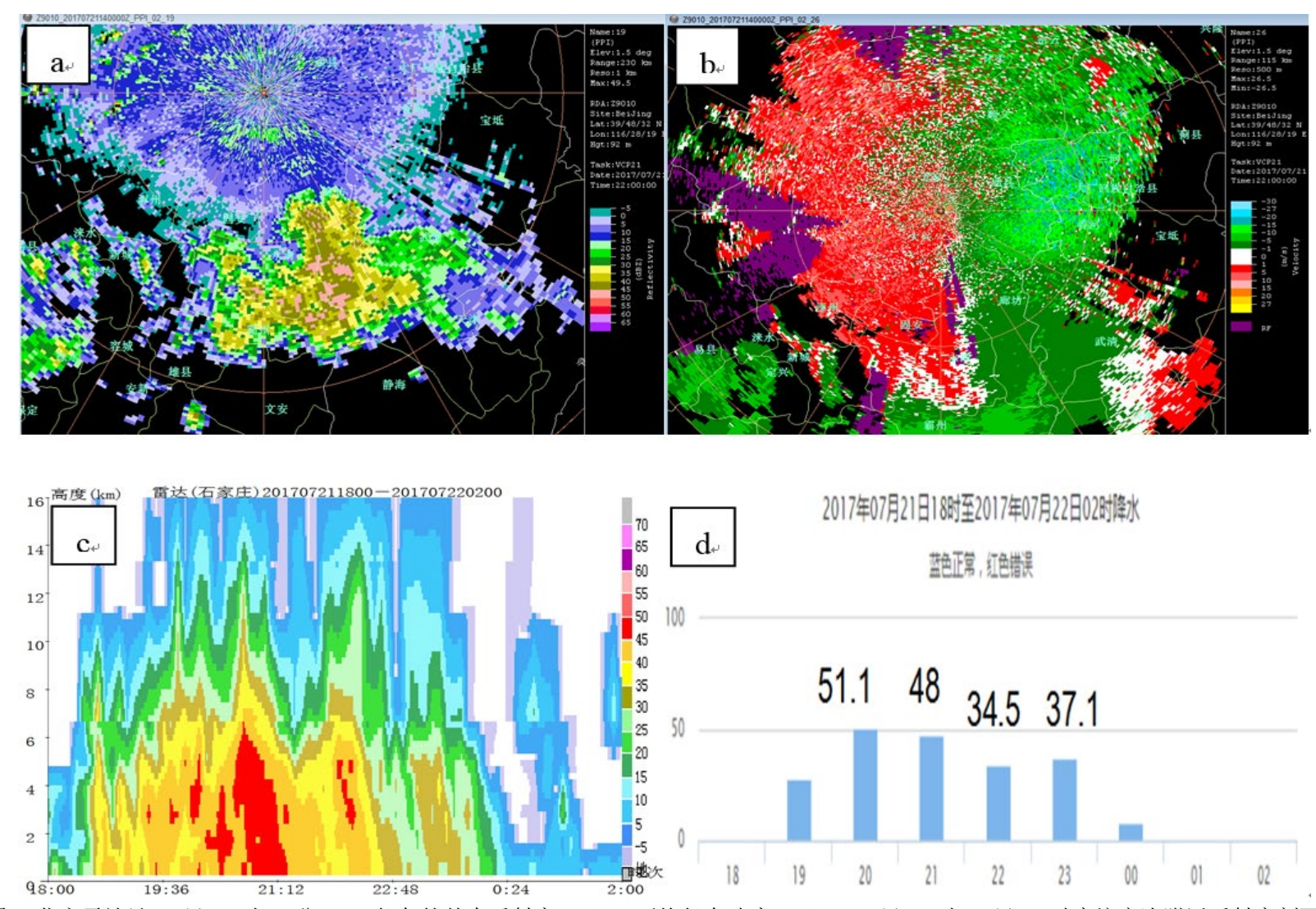

图 3. 北京雷达站 21 日 22 时 00 分 $1.5^{\circ}$ 仰角的基本反射率（a）、平均径向速度（b）；21日 18 时-22 日 02 时廊坊安次附近反射率剖面图 (c) 及对应小时降水量 (d)

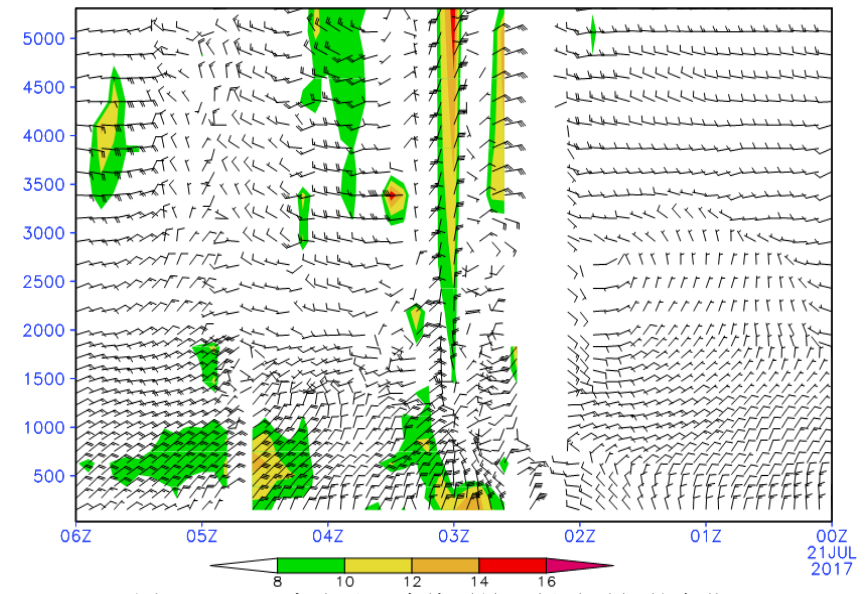

图 4.21 日石家庄站风廓线雷达风场随时间的变化

层达到了最大 $-4{ }^{\circ} \mathrm{C} / \mathrm{S}$ 。

因此, 石家庄暴雨是在低层切变线移出以后, 由边 界层东北风触发对流，配合局地良好的水汽、能量和不 稳定条件，对流迅速发展成结构完整的中尺度对流系统 并缓慢移动, 造成局地暴雨天气。

廊坊暴雨发生时, 西风带系统已过境, 副高进一步 北抬, 廊坊地区位于 588 线南侧。大厂站风廓线雷达风 场（图 5) 显示, 21 日上午冷空气南压, 400-800 m 边 界层偏东风风速可达 $15 \mathrm{~m} / \mathrm{s}$ 以上, 11-15 时东北风或偏 东风风速减小, 15 时以后偏东风风速开始增加, 伴随有 对流单体不断生成并发展, 降水集中在 20 时以后, 此时
边界层有中尺度浴旋过境, 而这很有可能与降水的潜热 反馈有关。这种边界层偏东风的脉动以及潜热反馈产生 的中尺度浴旋, 很可能是廊坊地区小尺度对流单体的触 发和长时间维持机制。

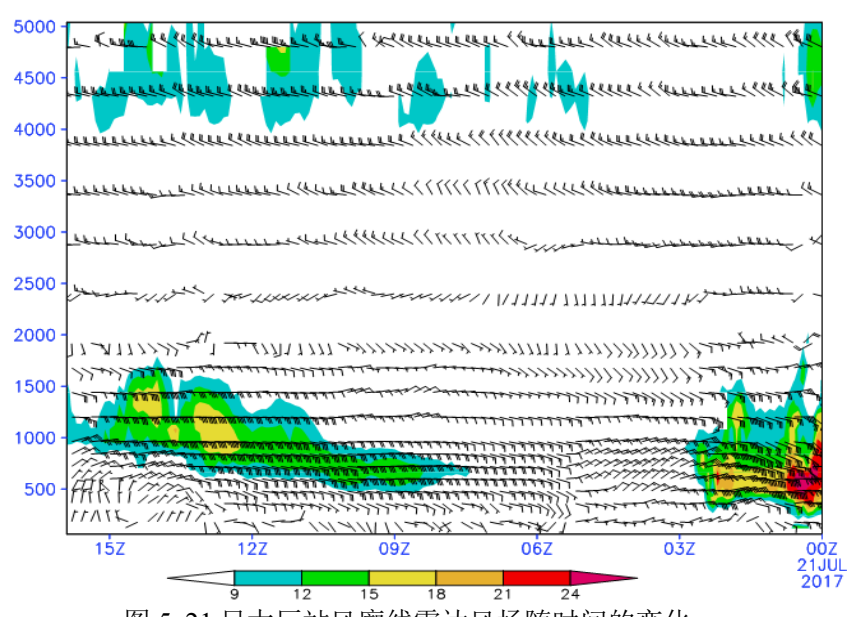

图 5.21 日大厂站风廓线雷达风场随时间的变化

\section{V. 结论}

盛夏季节, 副高持续北抬, 中低层冷空气影响, 发生 在夏季风控制区内的本次局地暴雨, 雨量分布极为不 均, 暴雨区的中尺度特征和触发机制也各有不同:

1. 三个暴雨区的雷达回波基本均以积状云对流回波 为主, 结构密实, 对流单体质心低、降水效率高。但秦 
皇岛地区受切变线影响, 回波呈带状, 多个对流单体形 成列车效应相继影响; 石家庄和廊坊地区回波是局地生 成、呈块状、移动缓慢。

2. 秦皇岛地区天气尺度动力强迫明显, 由中低层切 变线和地面冷锋触发, 有大尺度辐合上升运动和水汽输 送相配合; 石家庄和廊坊地区暴雨由边界层风场触发中 小尺度对流系统, 并在不稳定层结、高温高湿高能条件 和潜热反馈效应下得以加强和发展。

\section{致谢}

本文受国家自然科学基金委员会科研项目 “渤海西岸 及近岸海域准圆形 M a CS 多尺度结构及演变的研究”

（编号：41575049）和河北省气象局强对流创新团队联 合资助。

\section{参考文献}

[1] 朱乾根, 林锦瑞, 寿绍文, 唐东昇. 天气学原理. 北京: 气象出版社, 2007 年, pp. 480 .
[2] 郭锐, 付宗钰. “华北两次副高边缘暴雨过程卫星云图释用, ”气象 科技, vol. 41, issue 6, pp.1095-1100, 2013.

[3] 王宗敏, 丁一汇, 张迎新, 李江波, 田利庆, 赵玉广. “西太平洋副热 带高压的边界特征及其附近暖区对流雨带成因,”气象学报, vol. 3, pp.417-427, 2014

[4] 王宗敏, 丁一汇, 张迎新, 田利庆, 李江波. “副高外围对流雨带中的 对流-对称不稳定及锋生的诊断分析, ” 大气科学, vol. 38, issue 1, pp.133-145, 2014

[5] 孙建华, 赵思雄, 傅慎明, 汪汇洁, 郑淋淋. “2012 年 7 月 21 日北京

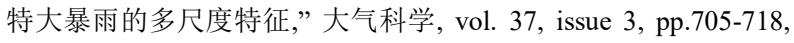
2013.

[6] 甘璐, 郭文利, 邓长菊. “北京地区两次特大暴雨过程的对比分析, ” 干旱气象, vol. 35, issue 2, pp.239-249, 2017.

[7] 王安宇, 吴池胜, 林文实, 杨艳, 冯瑞权, 古志明, “关于我国东部夏 季风进退的定义,”高原气象, vol. 18, issue 3, pp.400-408, 1999.

[8] 江志红, 何金海, 李建平, 杨金虎, 王冀. “东亚夏季风推进过程的气 候特征及其年代际变化,”地理学报, vol. 61, issue 7, pp.675-686, 2006.

[9] 李栋梁, 邵鹏程, 王慧, 陈练. “中国东亚副热带夏季风北边缘带研 究进展,”高原气象, vol. 32, issue 1, pp.305-314, 2013. 